Conclusion Summer school is a meaningful addition to our education programme and due to this success, is to be extended in the future to cover other school holidays. Summer school has also proved to be a valuable opportunity to promote the philosophy of palliative care to those of a younger generation.

\section{P-258 EXTENDING THE CURRICULUM: BRINGING END OF LIFE CARE (EOLC) INTO THE CLASSROOM FOR YEAR 11 AND 13 STUDENTS}

Katherine Birch. Compton Hospice, Wolverhampton, UK

10.1136/bmjspcare-2017-hospice.283

Background In the past, death was such a part of everyday life it was simply and frankly discussed, but such opportunities for today's young adults are more limited. Whilst encouraging people of all ages to talk more about death and dying is important, for those considering a health-related career, having a better understanding about life-limiting illnesses and end of life care is particularly important. With many of those entering the caring professions expressing feelings of anxiety and fear in relation to death and the dying patient (Dakin, 2003) and a recognition that student nurses/doctors find caring for dying patients stress-inducing (Arber, 2001; Timmins \& Kaliszer, 2002), more needs to be done to engage young adults with topics such as complex, life-limiting illnesses, death and dying (Wardhere, 2014).

Project Reflecting this, an innovative six- week programme, 'Caring for Dave', was designed by Compton Hospice for Health Futures University Technical College, West Bromwich the first UTC in the country with healthcare and health sciences as its specialism. This challenging programme followed 'Dave' from an initial concern about his health through to care after death. Each week explored a different topic - such as lifestyles and health, breaking bad news, the dying process and caring for Dave after death. Students also completed work between sessions to enhance and consolidate their learning.

The aim of the project was to:

- Provide insight into eolc and related topics for students interested in a career in the care sector

- Explore death and dying from a range of perspectives

- Consider the personal competencies/attributes necessary to care for someone who is dying

- Encourage learners to think about a career in palliative/ eolc.

Evaluations provided very positive feedback about the programme from staff and student perspectives and the hospice is currently working with UTC and other sixth forms to explore wider roll out.

\section{P-259 INTRODUCTION OF REFLECTIVE PRACTICE FOR MEDICAL STUDENTS ON THEIR PLACEMENT IN A HOSPICE}

Rebecca Avis, Sarah Parnacott. Ashgate Hospicecare, Chesterfield, UK

\subsection{6/bmjspcare-2017-hospice.284}

Background A recent study in postgraduate education found that reflection played a vital role in helping junior doctors to learn from clinical experience. All UK doctors are expected to undertake reflection and to make this an essential foundation for lifelong learning. Medical students have an attachment with the hospice for one week during their fourth year of medical training. During this time they work with our teams on the inpatient unit, the day hospice, and in the community. Following the EAPC conference (June, 2016) when Jason Boland looked at the themes of written reflection amongst medical students in Hull, we implemented the use of a reflective piece for all our students. We sought consent from the students that their reflection be anonymised and be used to educate other professionals.

Aims To introduce reflection as a beneficial practice to students for lifelong learning.

Methods The students were asked to submit a 300- word article at the end of the week to the speciality doctor, in which they reflected upon a situation encountered during their week at the hospice that they felt had impacted upon them.

Results The range of topics was diverse and included 'The impact of certifying a patient', 'Being present when a patient or relative has been given bad news', 'A patient who wished to go to Dignitas' and 'Caring for young patients'. The medical students valued the opportunity in a supportive environment to carefully review, reflect and discuss different emotive situations that they had found surprising, distressing or inspiring during their placement. This in itself was cathartic and enabled them to receive appropriate emotional support and signposting if required to other support services before finishing the attachment.

Conclusion Reflection is a valuable tool in experiential learning, we hope this experience will endorse the value of reflective practice in their future careers.

\section{P-260 A 'CAN DO ATTITUDE' ENABLES LEARNING DISABILITIES STUDENTS TO EXPERIENCE WORK}

${ }^{1}$ Tricia Wilcocks, ${ }^{2}$ Fay Elliot. ${ }^{1}$ Ellenor Gravesend, UK; ${ }^{2}$ Ifield 19+ College, Gravesend, UK

10.1136/bmjspcare-2017-hospice.285

Background Students with Learning Disabilities (LD) are encouraged to continue in education or training to the age of 25 (Department for Education, 2016). Moving from education into work requires a supportive and structured approach. An innovative programme was established by the $19+$ college to secure supported work placements for this cohort of students. When approached the hospice was initially cautious, however, we were encouraged by the level of support on offer.

Aim To support adults with learning disabilities towards independent employment.

Method Job Coaches from the college accompanied each student with LD, ensuring they understood instructions and carried out tasks to a good standard. Placements were sought where routine tasks could be allocated for the student to learn and master and were monitored by the college. Each placement was offered initially for one academic year. Job Coaches were to pull back and observe from a distance encouraging and supporting the student to undertake tasks independently when ready. When agreed, the student would begin to attend on their own for part or a full day, working towards independence.

Results Two students attended placements all year; one in retail and he has been working towards independence; another one in the gardening and catering teams and he has been 